\title{
Coronavírus: exame preliminar da trajetória científica e tecnológica dos surtos
}

\author{
Coronavirus: preliminary examination of the scientific and \\ technological trajectory of outbreaks
}

Célia Regina Simonetti Barbalho ${ }^{a}$ *

Layde Dayelle dos Santos Queiroz ${ }^{\mathrm{b}}$

Paulo Alexandre do Couto Simonettic

Sammy Aquino Pereirad (iD

Simone Santos de Freitas ${ }^{b}$ (D)

\begin{abstract}
RESUMO: Traça um exame preliminar de como se constituiu a relação entre manifestações da doença, descobertas científicas e produção tecnológica para os principais surtos de coronavírus, entre 2000 a 2020, de modo a adensar conhecimentos que possam corroborar para a compreensão ampliada da pandemia. Adota como assuntos basilares para a revisão bibliográfica a interlocução entre ciência, tecnologia e inovação bem como os aspectos relevantes para compreensão da trajetória da família coronavírus: principais surtos (2002, 2012 e 2019) e descobertas científicas. Apresenta uma linha do tempo dos surtos provocados pelo vírus visando compor um quadro com a trajetória das principais descobertas realizadas pela comunidade científica que estuda a temática, apoiada nos estudos de Weiss (2020). Por meio de um estudo de anterioridade realizado no Questel Orbit, dimensiona os pedidos de patentes por família existentes destacando o período temporal da publicação, principais países de depósito, clusters e domínios tecnológicos e série histórica pela Classificação Internacional de Patentes (CIP). Avalia as trajetórias expostas e conclui que é necessário um maior alinhamento entre a ciência, a tecnologia e a inovação para promover respostas rápidas e contundentes para as doenças geradas pelo Coronavírus.
\end{abstract}

Palavras-chave: Coronavírus; Patentes; Inovação; Informação tecnológica.

ABSTRACT: It outlines a preliminary examination of how the relationship between manifestations of the disease, scientific discoveries and technological production for the main outbreaks of the coronavirus, between 2000 and 2020, was established in order to consolidate knowledge that can corroborate for an expanded understanding of the pandemic. It adopts as basic subjects for the bibliographic review the interlocution between science, technology and innovation as well as the relevant aspects for understanding the trajectory of the coronavirus family: main outbreaks (2002, 2012 and 2019) and scientific discoveries. It presents a timeline of outbreaks caused by the virus in order to compose a picture with the trajectory of the main discoveries made by the scientific community that studies the theme, supported by the studies by Weiss (2020). Through a previous study carried out in Questel Orbit, it measures the patent applications per existing family, highlighting the period of publication, main filing countries, clusters and technological domains and historical series by the International Patent Classification (CIP). It evaluates the exposed trajectories and concludes that a greater alignment between science, technology and innovation is necessary to promote quick and forceful responses to the diseases generated by the coronavirus.

Keywords: Coronavírus; Patents; Innovation; Technological information.

a Faculdade de Informação e Comunicação, Universidade Federal do Amazonas, Manaus, AM, Brasil.

b Programa de Pós-Graduação em Propriedade Intelectual e Transferência de Tecnologia para a Inovação, Universidade Federal do Amazonas, Manaus, AM, Brasil.

c Programa de Pós-Graduação em Biotecnologia com foco em Gestão da Inovação, Universidade Federal do Amazonas, Manaus, AM, Brasil.

d Arranjo de NIT da Amazônia Ocidental (Arranjo AMOCI), Instituto Nacional de Pesquisas da Amazônia, Manaus, AM, Brasil.

*Correspondência para/Correspondence to: Célia Regina Simonetti Barbalho. E-mail: simonetti@ufam.edu.br.

Recebido em/Received: 15/08/2020; Aprovado em/Approved: 17/12/2020.

Artigo publicado em acesso aberto sob licença CC BY 4.0 Internacional $@()$ 


\section{INTRODUÇÃO}

Desde a Antiguidade, o homem emprega sua criatividade para constituir elementos que expandam sua qualidade de vida. Esta capacidade criadora colabora para gerar inovações que contribuam de forma significativa para equacionar problemas de diversos domínios de modo a oferecer elementos que possam assegurar o bem-estar da sociedade.

No contexto atual, em que uma doença amplamente disseminada causada pela família viral coronaviridae, está atuando agressivamente em todos os continentes do planeta, a construção de soluções para evitar, prevenir ou minimizar as consequências desse evento de modo a socorrer e assistir as populações atingidas e restabelecer o bemestar global, perpassa pelo emprego da criatividade humana que se manifesta por meio da atividade investigativa e inovadora.

A ciência, a tecnologia e a inovação se configuram, de fato, como uma engrenagem fundamental que deve ser alinhada de forma eficaz para combater o grau de incerteza e complexidade causado pela pandemia. Essa trilogia se apoia no acúmulo de conhecimento já produzido, de modo a otimizar soluções com valor agregado para os problemas gerados.

Considerando a importância de discutir evolução histórica do desenvolvimento científico, tecnológico e inovativo que envolve o coronavírus, com o intuito de contribuir para o entendimento da trajetória constituída para equacionar os problemas gerados pelos principais surtos da doença ao longo do tempo, a proposta deste trabalho é examinar a possível existência da relação entre manifestações da doença, descobertas científicas e produção tecnológica de modo a adensar conhecimentos que possam corroborar para a compreensão ampliada da pandemia global.

Este artigo apresenta parte dos resultados da pesquisa intitulada Prospecção tecnológica das patentes para o tratamento de doenças causadas pela família viral Coronaviridae, desenvolvida pelo grupo de pesquisa Gestão da Informação e do Conhecimento na Amazônia da Universidade Federal do Amazonas.

Para atender ao proposto, este estudo é composto por cinco fragmentos, além da introdução, que visam apontar inicialmente, a problematização da pesquisa e o percurso metodológico construído para atingir os objetivos propostos e que conduziu ao levantamento de dados. No quarto fragmento são expostas as bases teóricas por meio do exame de dois temas relevantes: ciência e tecnologia, bem como as trajetórias da família coronavírus. Os resultados obtidos são discutidos na penúltima parte do trabalho, conduzindo para as conclusões do estudo.

\section{PROBLEMA}

A urgência de lidar com o novo surto de coronavírus denominado pela Organização Mundial de Saúde (OMS) como SARS-CoV-2 ou covid-19, que se expandiu de modo célere para todos os continentes, demanda o exame de um conjunto de conhecimentos, científicos e tecnológicos, que foram construídos ao longo da manifestação das doenças que eles provocam em seres humanos no esforço de colaborar para o entrelaçamento entre o estoque de saberes já produzidos e os que estão em processo de maturação e criação, de modo a legitimar o ciclo virtuoso da ciência em busca de respostas positivas para os problemas que a sociedade enfrenta.

Para colaborar com os esforços que estão sendo conduzidos, na expectativa de subsidiar melhorias que possam acelerar os resultados positivos para aplacar os 
problemas causados pelo vírus, este estudo está pautado na seguinte questão norteadora: há um alinhamento entre a trajetória dos surtos ocorridos em 2002, 2012 e 2019, as descobertas e as tecnologias protegidas para as doenças causadas pela família viral coronaviridae?

A resposta a esta questão perpassa pelo entendimento de alguns aspectos teóricos que amparam o recorte oferecido pela pesquisa.

\section{PERCURSO METODOLÓGICO}

Esta pesquisa exploratória de natureza quali-quantitativa, foi instituída, como exposto, com o objetivo de examinar um possível alinhamento entre manifestações das doenças causadas pela família coronavírus, as descobertas científicas e produção tecnológica, sendo os dois primeiros pontos amparados por estudo teórico.

Para o exame da produção tecnológica realizou-se um mapeamento de pedidos de patentes relacionadas ao coronavírus, considerando os surtos da doença expostos na Figura 1. O estudo prospectivo foi realizado a partir das informações patentárias obtidas por meio de um levantamento realizado na base de dados de patentes Questel Orbit, que cobre publicações de 87 escritórios nacionais e 6 escritórios regionais (EPO, WIPO, OAPI, ARIPO, EAPO e CGC) (ORBIT, 2019). A análise e exportação de publicações foram agrupadas em famílias de patentes visando favorecer o entendimento amplo dos dados levantados.

Para que a estratégia de busca fosse, de fato, adequada para recuperar o objeto de interesse dos pesquisadores, testes foram realizados no Orbit, para que assim os resultados estivessem dentro dos parâmetros de pesquisa definidos. Desta forma, a estratégia utilizada foi (Severe Acute Respiratory Syndrome_SARS OR SARS_CoV OR Middle East Respiratory Syndrome_MERS OR MERS_CoV OR Severe Acute Respiratory Syndrome Coronavírus 2 OR 2019_nCoV OR SARS_CoV_2 OR Covid_19).

As palavras-chave associadas à estratégia de busca foram escolhidas a partir da literatura científica, haja vista a busca objetivou identificar também pedidos de patentes e patentes relacionadas aos principais surtos anteriores ao de 2019, ou seja, o SARS, MERS e SARS-COV-2 (Figura 1).

Ao utilizar a estratégia de busca no Orbit, todos os campos disponíveis para a recuperação dos termos foram marcados, com a intenção de obter um resultado mais abrangente para que posteriormente fosse mais bem delimitado. Os campos utilizados foram título, resumo, reivindicações, descrição, objeto da invenção, vantagens e desvantagens sobre o estado da arte anterior, reivindicações independentes, conceitos e textos completos, aplicando o operador booleano OR com o objetivo de buscar um ou outro termo, e o de proximidade underline que indica a conexão de dois termos em uma única palavra ou em duas palavras separadas adjacentes.

Neste processo foram recuperados 4.904 pedidos de patentes e patentes, a partir dos quais traçou-se um panorama preliminar por meio das ferramentas de visualização de dados em gráficos do Orbit. Dentre as diversas opções de visualização, optou-se por partir da análise das informações sobre os países onde foram depositados os pedidos de patentes ou patentes, clusters de tecnologia e domínio tecnológico, geradas pelo Orbit e por um elemento demonstrativo do quantitativo por ano para compreender a evolução dos depósitos, bem como uma das cinco principais classificações de patentes (CIP) por período temporal para viabilizar a compreensão das temáticas protegidas. 
Os resultados foram agrupados pela própria plataforma em faixas temporais, dentre as quais elegeu-se um conjunto de quatro janelas de tempo de modo a englobar os períodos dos principais surtos do coronavírus (Figura 1).

Figura 1: Divisão temporal do levantamento de patentes.

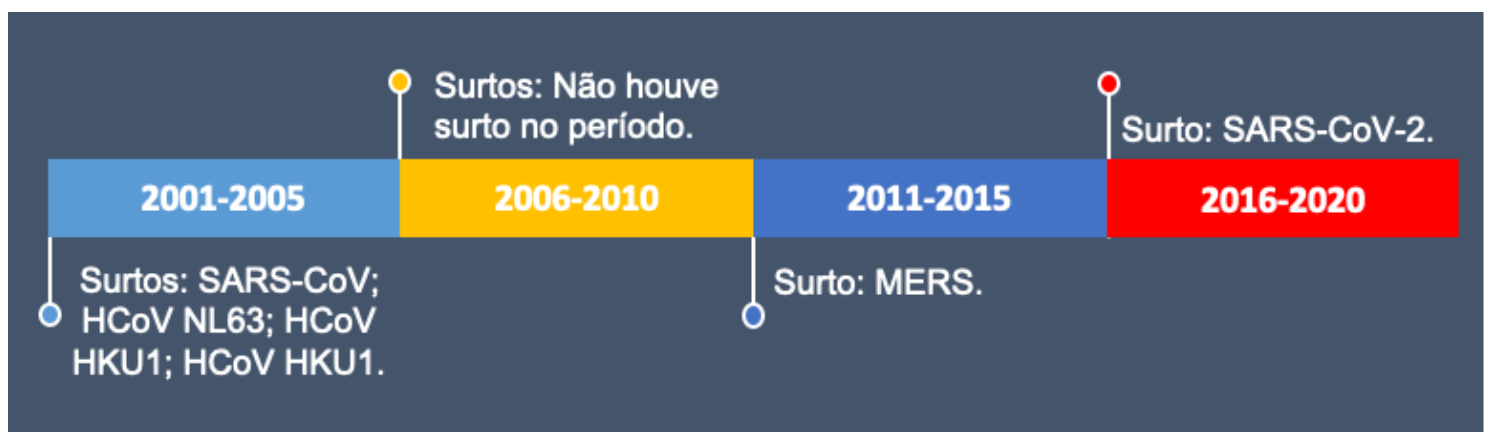

Fonte: Elaboração dos autores (2020).

Pela Figura 1, pode-se observar que o período 2006-2010 não houve surto, entretanto, em se tratando de um levantamento de informação tecnológica por meio de pedidos de patentes e patentes, é importante observar que este tipo de fonte tem uma dinâmica própria de publicação fazendo com que este período fosse contemplado no escopo da pesquisa.

De cada grupo foram destacadas as cinco Classificações Internacionais de Patentes (CIPs) mais ocorrentes. Cabe destacar que essa classificação, que surgiu em 1971 e divide os assuntos em oito seções, variando de $\mathrm{A}$ à $\mathrm{H}$, teve como o objetivo agrupar as áreas tecnológicas. Este agrupamento facilita a identificação de semelhanças tecnológicas e ajuda no processo de investigação do estado da técnica da arte (PRIESNITZ et al., 2015).

A partir das cinco CIPs mais ocorrentes foram gerados gráficos que permitissem a melhor visualização e análise histórica destas tecnologias em relação aos casos de coronavírus já ocorridos.

Um levantamento quantitativo da produção científica foi realizado na base de dados Scopus com a estratégia TITLE-ABS-KEY ("Severe Acute Respiratory Syndrome-SARS" OR sars-cov OR "Middle East Respiratory Syndrome-MERS" OR mers-cov OR "Severe Acute Respiratory Syndrome Coronavírus 2" OR 2019-ncov OR sars-cov-2 OR covid-19), com o intuito de identificar o quantitativo de trabalhos disponibilizados nos períodos estratificados. Não foi objeto desse levantamento o exame dos conteúdos localizados, mas somente compor um breve quadro comparativo quantitativo entre artigos e pedidos de patentes nos resultados, considerando que um estudo mais aprofundado sobre a produção científica envolve questões como autoria e co-autoria, dentre outros, não presentes na proposta dessa pesquisa.

\section{CIÊNCIA \& TECNOLOGIA: PONTES PARA COMPREENDER A CAMINHADA}

Ao se referir sobre a relação entre ciência e tecnologia, Schwartzman et al. (1993), afirma que ambos se configuram como elementos de transformação capital para um país, sendo essenciais para elevar o padrão de vida da população, consolidar uma economia moderna e participar com plenitude em um mundo cada vez mais globalizado. 
No que pese a assertiva dos autores, é oportuno destacar que a ciência pauta sua ação na busca pela compreensão de fenômenos e seu funcionamento, elucidando as regras, procedimentos e sistemas que o fazem existir. O resultado final da ciência são teorias que explicam o que existe e como funciona. A tecnologia se apropria do conhecimento sobre determinado fenômeno para se adequar às necessidades humanas. $O$ propósito é utilitário. Entretanto ambas caminham juntas, uma vez que tecnologias se apropriam do conhecimento gerado pela ciência para aprimorar suas técnicas e a ciência emprega a tecnologia para realizar seus experimentos.

No que tange à ciência, de uma maneira geral, o ambiente acadêmico tem sido o principal provedor de conhecimento científico, por apresentar novas tecnologias ou até mesmo a melhoria de produtos, processos e serviços, agregando a estes a novidade para novos usos indispensáveis ao desenvolvimento social, humano e tecnológico local, regional, nacional e até mesmo mundial.

Corroborando para essa discussão, Garcia (2006) afirma que a pesquisa é o principal diferencial no processo de inovação, por representar não somente um salto tecnológico para a ciência, mas também pelo fato de promover inovações que movimentam o mercado competitivo.

Deste modo, o conhecimento disponível por meio de informações de cunho tecnológico, apresentados em documentos de patente, oferece o potencial não somente para a geração de novas inovações, como também a identificação de novos mercados, dos promotores de conhecimento (inventores), e dos principais players de mercado. Tradicionalmente, as patentes são vistas como um catalisador para pesquisa e inovação.

Atualmente, com a questão da pandemia causada pelo novo coronavírus, o SARS-CoV2, que provoca a doença chamada de covid-19, uma busca acelerada por uma vacina para prevenção da doença vem ocorrendo tendo em vista o tempo reduzido para obtêla de modo diminuir seus impactos muitas vezes fatais. Para tanto, foram realizadas buscas por tecnologias para tratamento de outros tipos de coronavírus, em bases de dados de pedidos de patentes e patentes, demonstrando o grau de importância que estas possuem (INPI, 2020).

Quintella et al. (2011, p. 408), afirma que estas pesquisas que objetivam levantar as tecnologias existentes em determinada temática, torna possível traçar um panorama de determinado domínio tecnológico, considerando os seus estágios de maturidade, mercado onde se insere, aplicabilidade, entre outros aspectos. Estes estudos também ampliam a visão de investidores e pesquisadores no que diz respeito às novas aplicações para tecnologias existentes, de forma que passem a ser úteis em novos mercados.

Enquanto um título temporário de propriedade, as patentes objetivam proteger novos produtos, processos ou aperfeiçoamentos que tenham aplicação industrial além de apresentarem uma solução tecnológica para um problema específico, durante um determinado tempo. Por reunirem informações tecnológicas significativas, estudos pautados em conteúdos por elas expostos são significativos para compreender o estado de uma técnica, por exemplo, empregando, dentre outros mecanismos, os elementos dispostos na Classificação Internacional de Patentes, que ordenam o seu conteúdo técnico "a fim de facilitar o acesso às informações tecnológicas e legais contidas nos mesmos." (INPI, 2019; TECNOPUC, 2020).

São estudos dessa natureza que refletem a sinergia entre ciência, tecnologia e inovação e dão lugar a trabalhos de prospecção tecnológica, por exemplo, empregados para minimizar incertezas uma vez que busca mapear e analisar 
sistematicamente o desenvolvimento científico e tecnológico com intuito de compreender seus impactos para a criação do futuro desejado, como no caso em foco neste estudo: o coronavírus.

\section{CORONAVÍRUS: TRAJETÓRIAS DE UMA SÍNDROME}

O coronavírus (CoV) é um grupo diversificado de vírus capaz de infectar humanos e uma ampla variedade de animais causando doenças respiratórias, gastrointestinais, hepáticas e neurológicas, que vão desde males leves até a morte. Eles são classificados em vários gêneros se configurando em sete tipos principais, a saber: Alpha coronavírus 229 e NL63; Beta coronavírus OC43 e HKU1; SARS-CoV, causador da Síndrome Respiratória Aguda Grave ou SARS; MERS-CoV, causador da Síndrome Respiratória do Oriente Médio ou MERS e SARS-CoV-2, ou 2019-nCoV, causador da covid-19 (MCFEE, 2020).

Associados ao desencadeamento de infecções respiratórias, provocando desde sintomas mais leves, semelhantes aos resfriados, até casos mais complexos, como síndromes respiratórias graves, os coronavírus recebem o nome em função de sua forma no microscópio eletrônico. As partículas de vírus, de 50-150nm de diâmetro, são facilmente reconhecíveis por causa de sua forma pleomórfica, rodeada pela 'coroa' que consiste nas proteínas de pico de superfície estendida (PYRC; BERKHOUT; VAN DER HOEK, 2007).

Embora os coronavírus tenham sido identificados pela primeira vez em 1912, a partir do registro da primeira doença em animais - Peritonite Infecciosa Felina (FIPV)(MICHELLE HSIANG, 1999), eles só receberam notoriedade em 2003, quando um de seus membros foi identificado como o agente etiológico da síndrome respiratória aguda grave em seres humanos (PERLMAN; NETLAND, 2009), como pode ser observado na trajetória exposta na Figura 2.

Figura 2: Trajetória de identificação do coronavírus.

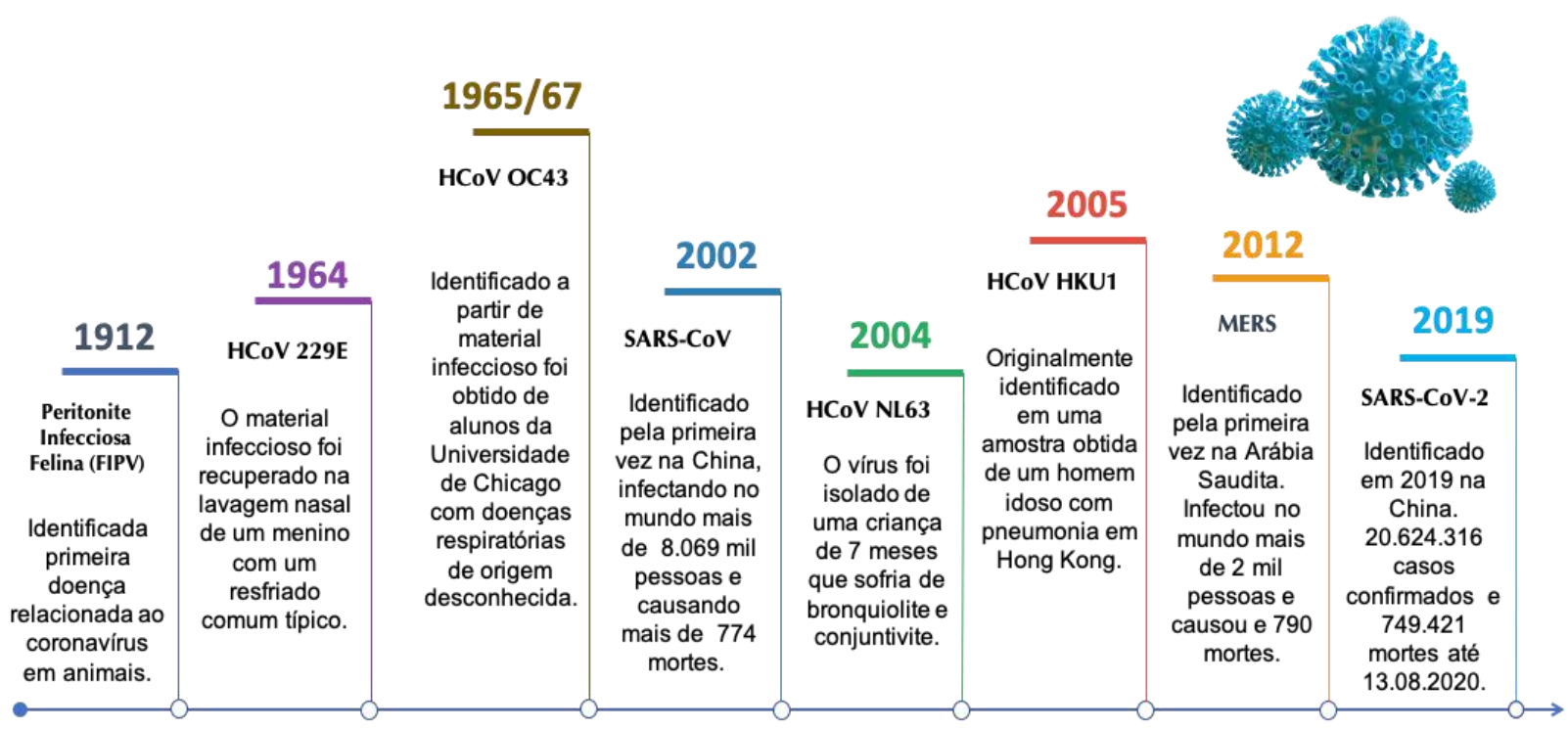

Fonte: Elaboração dos autores baseada em Michelle Hsiang (1999); Van der Hoek et al. (2004); Garbino et al. (2006); Pyrc, Berkhout e Van der Hoek (2007); Weiss (2020). 
A Figura 2 aponta que o HCoV-229E e o HCoV-OC43, descobertos na década dos anos de 1960, por quase 40 anos foram considerados os únicos representantes de coronavírus humanos. A epidemia de Severe Acute Respiratory Syndrome (SARS), que se manifestou inicialmente na província de Guandong, na China, provavelmente se originou de um reservatório de animal selvagem e foi responsável pelo surto que ocorreu em 2002 e 2003 e se espalhou por mais de 12 países incluindo Américas do Norte e do Sul, Europa e Ásia. Desde 2004 não existe relato de novos casos de SARSCOV (VAN DER HOEK et al., 2004).

A alta frequência de recombinação e taxa de mutação permite que os CoVs se adaptem a novos hospedeiros e ambientes, sendo os quatro mais comuns - 229E, NL63, OC43 e HKU1, responsáveis por quadros mais brandos de infecção respiratória. Outros dois tipos, o SARS-CoV e o Middle East Respiratory Syndrome (MERS) foram associados a quadros mais graves de infecção respiratória. O MERS, isolado em 2012, foi detectado pela primeira vez na Jordânia e na Arábia Saudita, além de outros países do Oriente Médio, Europa e África.

O terceiro coronavírus humano zoonótico ( $\mathrm{CoV}$ ) do século, ou seja, que pode ser transmitido entre o ser humano e outros animais, surgiu em dezembro de 2019, em um grupo de pacientes frequentadores do mercado de frutos do mar em Wuhan, província de Hubei, China. Semelhante às infecções SARS-CoV e MERS-CoV, os pacientes exibiram sintomas de pneumonia viral, incluindo febre, dificuldade respiratória e infiltração pulmonar bilateral nos casos mais graves.

No que pese a enorme diferença entre a propagação e disseminação dos dois primeiros para o último, o SARS-CoV-2 é o que apresenta menor índice de mortalidade girando em torno de $3 \%$ e $4 \%$, enquanto o índice do SARS foi de $10 \%$ e do MERS de $35 \%$. Ademais, além do potencial pandêmico e a célere capacidade de transmissão, o novo coronavírus, diferente dos outros que eram essencialmente respiratórios, causa em conjunto, problemas renais, cardíacos e nervosos, além de alterações na coagulação do sangue (MCFEE, 2020; Perlman; Netland, 2009).

Considerando o ciclo de doença causadas pelo coronavírus humano, em especial o emergente que surgiu em 2019 e desencadeou uma onda de infecção global, um conjunto de conhecimentos vem sendo produzido ao longo do tempo e disponibilizado para fortalecer soluções que possam auxiliar nas emergentes respostas, criando uma base técnico-científica colaborativa baseada em novos arranjos na comunidade científica, de modo a contribuir para acelerar o ambiente de inovação.

Ao destacar este cenário de produção de conhecimento sobre a temática, Weiss (2020, p.1) afirma que:

Na verdade, cada um desses eventos tem instigado um influxo de pesquisadores neste campo. Contudo, há uma longa história de pesquisa de coronavírus, começando já na década de 1930, que construiu uma grande base de conhecimento, bem como ferramentas técnicas para investigar esses patógenos humanos.

A autora, ao relatar o percurso de seu trabalho investigativo sobre o coronavírus ao longo de quarenta anos, apresenta uma linha do tempo (Figura 3) da evolução das pesquisas, dimensionando a trajetória científica dos estudos sobre o tema. 
Figura 3: Linha do tempo para pesquisa de coronavírus.

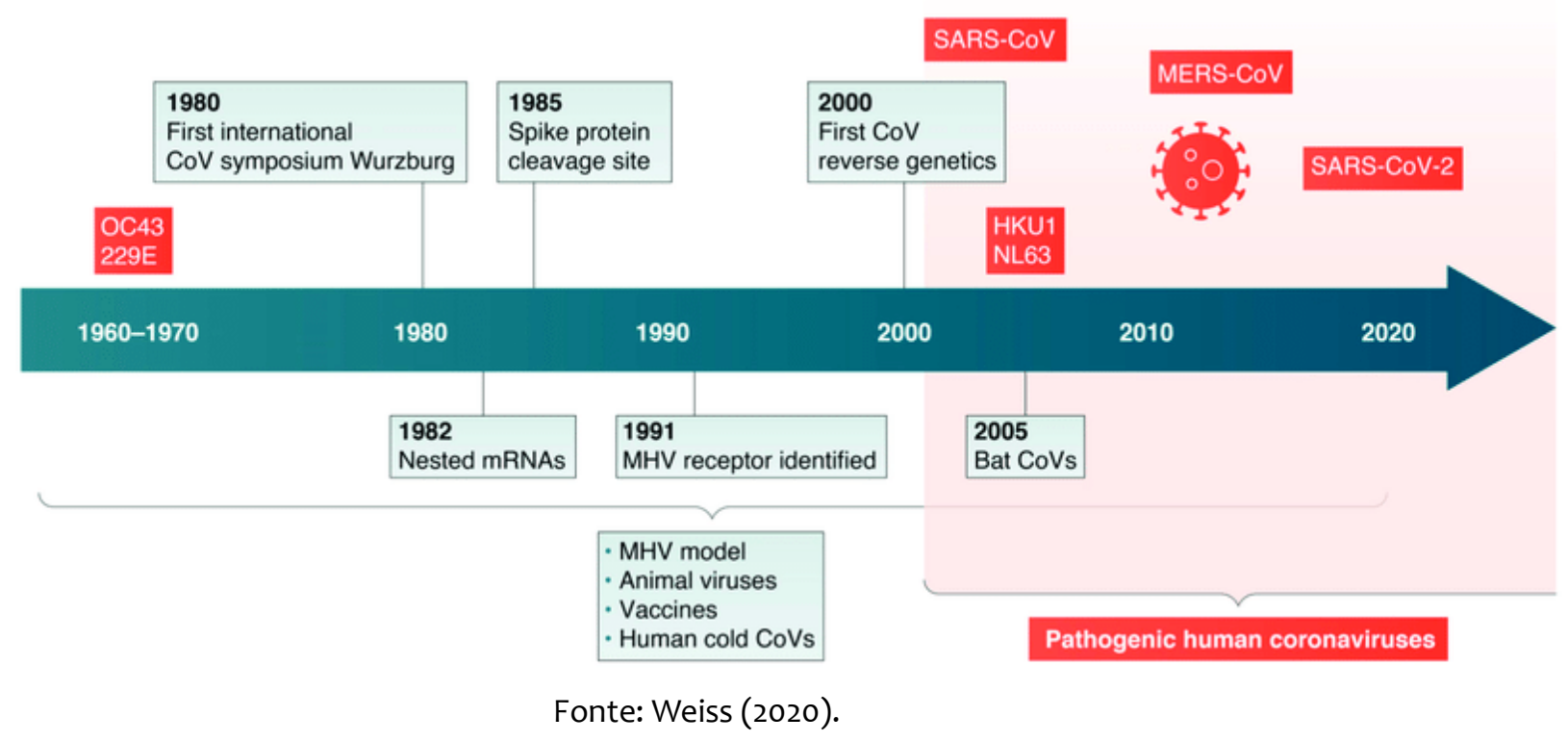

Ao relatar a evolução das descobertas científicas relativas ao coronavírus, a autora destaca os principais eventos, ressaltando que o covid-19 representou um sobressalto para a comunidade científica considerando a forma como surgiu, de maneira diferente dos demais, e o modo de se propagar com padrões diferentes. A Figura 3 permite inferir que as mais significativas descobertas até então, já haviam ocorrido quando da primeira manifestação em humanos.

No que pese a organização linear apresentada pela autora, é fato que o surto do novo coronavírus ampliou de forma significativa o olhar da comunidade científica para as investigações que apresentem uma solução de enfrentamento da doença dado o seu potencial para causar infecções letais em humanos, causando uma explosão de pesquisas sobre o vírus e a elevação exponencial da produção de conhecimento científico sobre a questão.

Contudo, o relato de Weiss (2020) destaca que embora haja uma longa história de pesquisa sobre o coronavírus, começando na década de 1930, a qual construiu uma grande base de conhecimento e ferramentas técnicas para as investigações, a comunidade de pesquisadores sobre o tema não é ampla e constante. A primeira conferência internacional da temática, em 1980, reuniu aproximadamente 60 pesquisadores que expuseram trabalhos sobre a incidência do vírus em animais e alguns trabalhos sobre o coronavírus humano $229 \mathrm{E}$, um agente mal compreendido do resfriado comum. Entretanto,

O surgimento do SARS-CoV foi a primeira vez que o público em geral, assim como muitos cientistas, tomou conhecimento desse grupo de vírus e seu potencial para causar infecções letais em humanos. Na verdade, cada um desses eventos tem instigado um influxo de pesquisadores neste campo. [...] Os surtos de coronavírus tiveram impactos significativos no campo de coronavírus antes pequeno e coeso. [...] À medida que o vírus desaparecia, o número de pessoas que trabalhavam com coronavírus diminuía. (WEISS, 2020, p. 2-3). 
Pela descrição de um pesquisador dedicado aos estudos sobre o CoV, pode-se inferir que o surto pandêmico causado pela covid-19 poderá contribuir na produção de novos conhecimentos sobre o vírus, impactando no surgimento de novas tecnologias que auxiliem no tratamento das doenças e possibilite prevenir ou combater rapidamente qualquer futuro surto.

No que diz respeito às tecnologias existentes e protegidas para o coronavírus, os estudos de Musyuni et al. (2020), Machuca-Martínez, Amado e Gutiérrez (2020), Kumar, Jung e Liang (2013), Yang et al. (2020) e Tietze et al. (2020), oferecem um panorama sobre as patentes de modo a compor uma resumida compreensão sobre o conhecimento tecnológico em questão.

O estudo de Musyuni et al. (2020) objetivou mapear o trabalho existente, por meio da análise da literatura de patentes, no campo dos coronavírus (CoV), particularmente o covid-19 (2019-nCoV). A análise das patentes, com foco nas tendências de cepas específicas de doenças CoV, pautou-se no escopo das reivindicações de 3800 documentos extraídos da Derwent Innovation. A análise mostrou que as principais áreas das invenções foram focadas no desenvolvimento de novos medicamentos e kits químicos ou biológicos para diagnóstico precoce, prevenção e gerenciamento de doenças.

Os autores chamam a atenção para uma área cinzenta em termos das tendências das inovações tecnológicas no gerenciamento de doenças em pacientes com CoV. Os resultados permitem ainda vislumbrar, segundo os autores, novas oportunidades de pesquisa e inovação tendo em vista que as informações disponíveis nos conjuntos de documentos analisados que se configuram como elementos para facilitar o trabalho dos formuladores de políticas, da academia, de institutos orientados à pesquisa e também investidores para tomarem melhores decisões em relação às etapas programadas de pesquisa e desenvolvimento para o diagnóstico, tratamento e tomada de medidas preventivas para CoV.

Machuca-Martínez, Amado e Gutiérrez (2020), apresentam o resultado de um levantamento de patentes para coronavírus obtidos pelo Orbit Intelligence usando a estrutura de família de patentes, que fornece uma visão geral da atividade de patenteamento e tendências na terapia antiviral focada com o uso de compostos à base de triazol, glicoproteína e inibidores de protease como possível tratamento. Os dados brutos são reportados em três subconjuntos classificados como: situação jurídica (ativa ou em domínio público), primeiro ano de aplicação (após 2015, 2011-2015, 2006-2010, 2001-2005) e cinco principais classificações internacionais de patentes (CIP). Os principais participantes, a tendência de investimento, mercados, distribuição geográfica, visão geral da tecnologia, distribuição de tecnologias e citação de patentes são apresentados de forma a compor um panorama geral do estudo.

Kumar, Jung e Liang (2013) revisaram as patentes publicadas no período de 2008 a 2013, com o intuito de examinar as intervenções terapêuticas que poderiam ser usadas na profilaxia e no tratamento da SARS, concluindo que existem soluções promissoras para combater da CoV que podem ser transformadas em medicamentos que possam ser úteis no combate à SARS e infecções virais relacionadas no futuro.

Yang et al. (2020) examinam as 240 patentes da medicina tradicional chinesa (MTC) com o objetivo de fornecer referência para a prevenção e tratamento do covid-19. Os resultados apontaram que as patentes se concentraram principalmente no tratamento sintomático de coronavírus, principalmente para melhoria dos sintomas respiratórios, como febre e tosse. 
O estudo de Tietze et al. (2020) identificou que a maioria das patentes relacionadas ao coronavírus giram em torno da química orgânica e do desenvolvimento de metodologias e medicamentos para prevenção, diagnóstico e tratamento de vírus. Conclui, confirmando os trabalhos dispostos que, pesquisa e patentes para invenções relacionadas ao coronavírus, não são novas. Os autores identificaram e analisaram três cenários nos quais emergem diferentes considerações sobre propriedade intelectual e sugerem três abordagens possíveis para lidar com essas questões durante uma pandemia, a saber, licenciamento compulsório, promessas e pool de propriedade intelectual.

Este breve panorama dos estudos de patentes sobre o coronavírus dimensiona a relevância que as informações tecnológicas possuem, as quais podem contribuir de forma significativa para o adensamento de novas informações no processo de inovação tecnológica. Contudo, os estudos sobre patentes para coronavírus carecem ser examinados à luz da trajetória da doença e das descobertas científicas de forma a compreender se o conhecimento inovador registrado corrobora para gerar benefícios para a sociedade como um todo.

\title{
RESULTADOS E DISCUSSÃO
}

O desenvolvimento tecnológico no combate a doenças pode estar associado a dois principais fatores: o lugar geográfico em que a doença se manifesta e a capacidade tecnológica, além do interesse de cada país em aportar esforços e recursos para o problema de saúde pública. Esses elementos se fazem presentes nas doenças causadas pelo coronavírus, conforme pode ser observado no trabalho de Fan et al. (2019, p. 210, grifo nosso), publicado em março, portanto antes do surto da covid-19. Os autores chamam a atenção para os surtos destacando que:

\begin{abstract}
Eles têm características comuns [...] como são todos altamente patogênicos para humanos ou gado, seus agentes originaram-se de morcegos, sendo dois deles originários da China. Portanto, é altamente provável que surtos futuros de SARS ou de coronavírus semelhantes ao MERS se originem de morcegos, e há uma probabilidade maior de que isso ocorra na China. Portanto, a investigação de coronavírus de morcego torna-se uma questão urgente para a detecção de sinais de alerta precoce, o que por sua vez minimiza o impacto de tais surtos futuros na China.
\end{abstract}

Ao chamar a atenção para a China, os autores confirmam que a localidade é um fator importante para a inovação tecnológica, contribuindo para que ela crie condições que favoreçam a geração de tecnologias capazes de enfrentar as doenças que podem ocorrer em seu território, considerando que sua manifestação afetará a população e atingirá todos os setores da sociedade, como pode ser observado no surto da covid19.

Nesse contexto, o Gráfico 1 apresenta a evolução quantitativa dos depósitos de pedidos de patentes por família sobre coronavírus, associada aos surtos ocorridos e que foram dimensionados na Figura 1. 


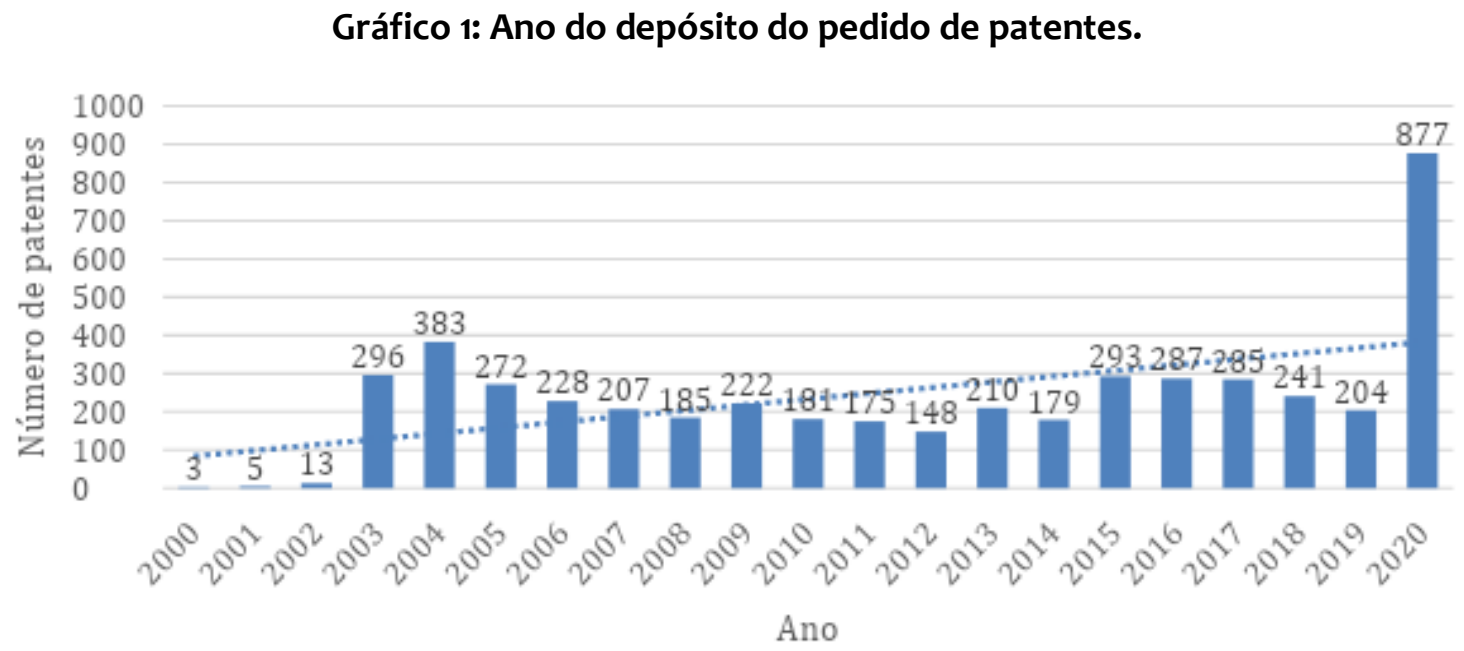

Fonte: Elaboração dos autores (2020).

No Gráfico 1 pode-se observar que o número de depósitos de pedidos de patentes, por família, cresceu 23 vezes do ano de 2002 ao ano de 2003, saindo de 13 patentes para 296 patentes. Ocorrência que está associada ao surto, em 2002, do SARS-CoV, na China. O número de patentes cresceu até 2004, quando a tendência passou a ser decrescente. Em 2009 houve um crescimento também, maior que em 2013. No entanto, em 2013, o número de depósitos voltou a crescer. Essa inversão de tendência ocorreu próximo do surto de MERS na Arábia Saudita, em 2012. Assim como o surto chinês, após a endemia árabe, os anos seguintes foram acompanhados de altos números de patentes associada a essa classe de vírus, seguido de uma decrescente que só voltou a aumentar de forma exponencial em 2020 com o surto SARS-CoV-2, que iniciou na China final de 2019, conhecido como a pandemia do covid-19.

No que pese os depósitos de pedidos de patentes de 2020 provavelmente não refletirem ainda o esforço científico em torno da covid-19, dado o período legal para de divulgação dos pedidos, muitos escritórios vêm atuando para acelerar velozmente as solicitações dada às questões humanas que envolvem a pandemia. Contudo, a partir do número de patentes por ano, pode-se inferir uma grande influência do desenvolvimento técnico-científico das patentes de acordo com a necessidade de controle de surtos epidemiológicos.

Os dados expressos no Gráfico 1 possibilitam também avaliar, no recorte temporal da pesquisa, que o período de 2016-2020, 39\% possui dos pedidos de patentes depositadas, enquanto 2006-2010, tem 21\%, 2011-2015 e 2001-2005 com $20 \%$ cada. O surto da MERS em 2012, foi considerado o mais fatal, causando o mais elevado número percentual de mortes, como já destacado, superando a mortalidade do covid-19, embora tenha atingido uma parcela muito menor da população. Nesse sentido, a inovação tecnológica disposta nos pedidos de patentes para enfrentamento desse coronavírus não reflete o impacto causado pelo surto. Observa-se que o maior número está relacionado ao período mais recente, o que pode ser indicativo de um processo evolutivo dos conhecimentos produzidos a partir do último surto, refletindo na pandemia que iniciou em 2019.

Considerando que um dos fatores de desenvolvimento tecnológico no combate a doenças é o lugar geográfico, como afirmado, o Gráfico 2 destaca a situação global dos locais onde foram solicitadas proteções das inovações patenteadas. 


\section{Gráfico 2: Principais países de tecnologia patenteadas sobre coronavírus em humanos.}

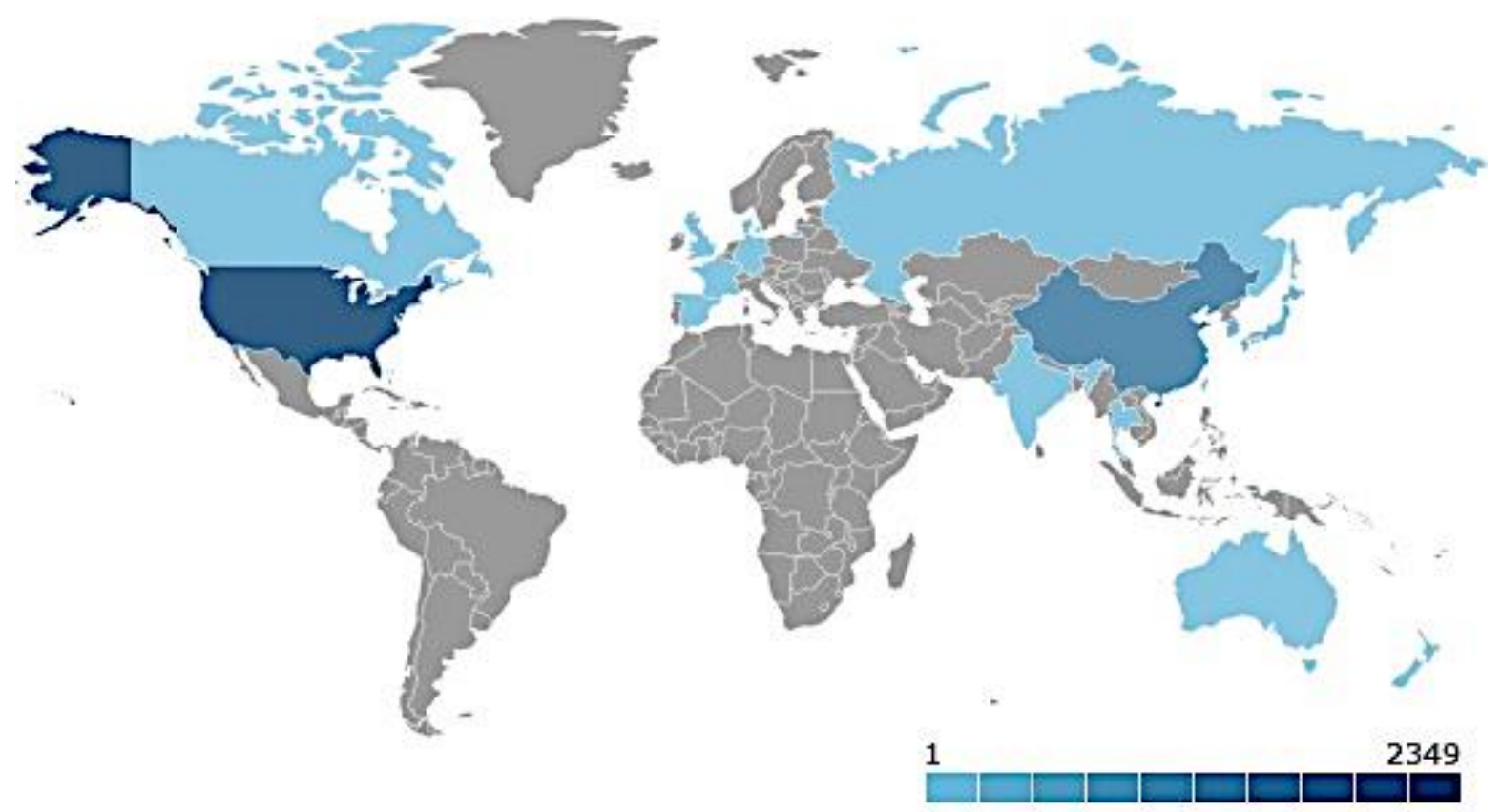

Fonte: Orbit (2020).

O Gráfico 2, mostra o número de pedidos prioritários protocolados nos diversos escritórios nacionais. Quanto mais intenso os tons de azul maior o número de pedidos naquele país. Observa-se que essencialmente EUA e China são os mais expressivos detentores dessas patentes. Segundo a WIPO (2012) os EUA dominam o cenário de patentes no que tange a vacinas contra doenças infecciosas e a China apresenta uma crescente trajetória nos últimos anos.

Dentre os registros de pedidos de patentes, os internacionais (WO) apresentam grande expressão, visto que as epidemias tendem a se alastrar, resultando em um interesse de mercado para proteção de tecnologias em nível mundial.

Quando analisadas por período temporal, o mapa se configura como mostra a Figura 4. 
Figura 4: Depósito de pedidos de patentes por país e período.
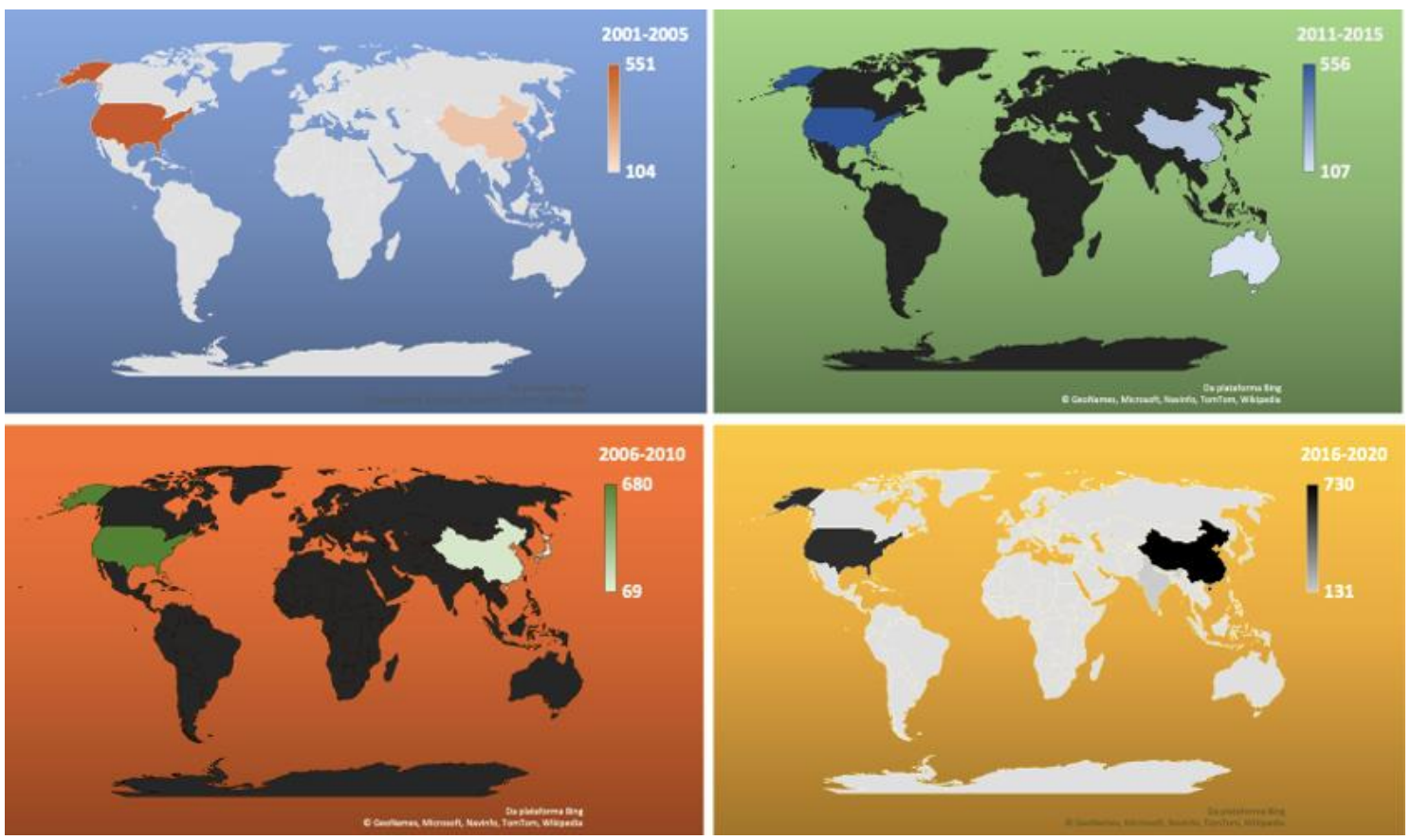

Fonte: Elaboração dos autores (2020).

O extrato pelos períodos temporais estabelecidos pela pesquisa com os dados dos principais países dos pedidos prioritários protocolados nos 87 escritórios nacionais e 6 escritórios regionais, aponta que em todos os períodos os Estados Unidos e a China foram os países onde se buscou maior proteção indicando a preocupação em proteger as tecnologias em países populosos e com um amplo mercado. O Japão, Coréia, Índia e Austrália foram os outros países com maior número de pedidos de proteção das inovações.

Observa-se que não há uma relação entre os anos dos surtos e os locais de maior incidência com os pedidos de patentes por país. É notório que a China, local onde iniciou o surto de SARS e de COVD-19, está presente de modo significativo em todos os extratos temporais, contudo não há indícios para relacionar as solicitações de patentes com a doença especialmente se for considerado que a China, de um modo geral, é o país com maior número de patentes no mundo.

O Gráfico 3 ilustra o conjunto de pedidos de patentes agrupadas de acordo com a proximidade semântica. Para cada cluster identificado por cores diferentes são representados vários pontos que significam uma família de patente. Três conceitos estatisticamente mais relevantes são mostrados para cada cluster. 
Gráfico 3: Representação da paisagem por clusters tecnológicos.

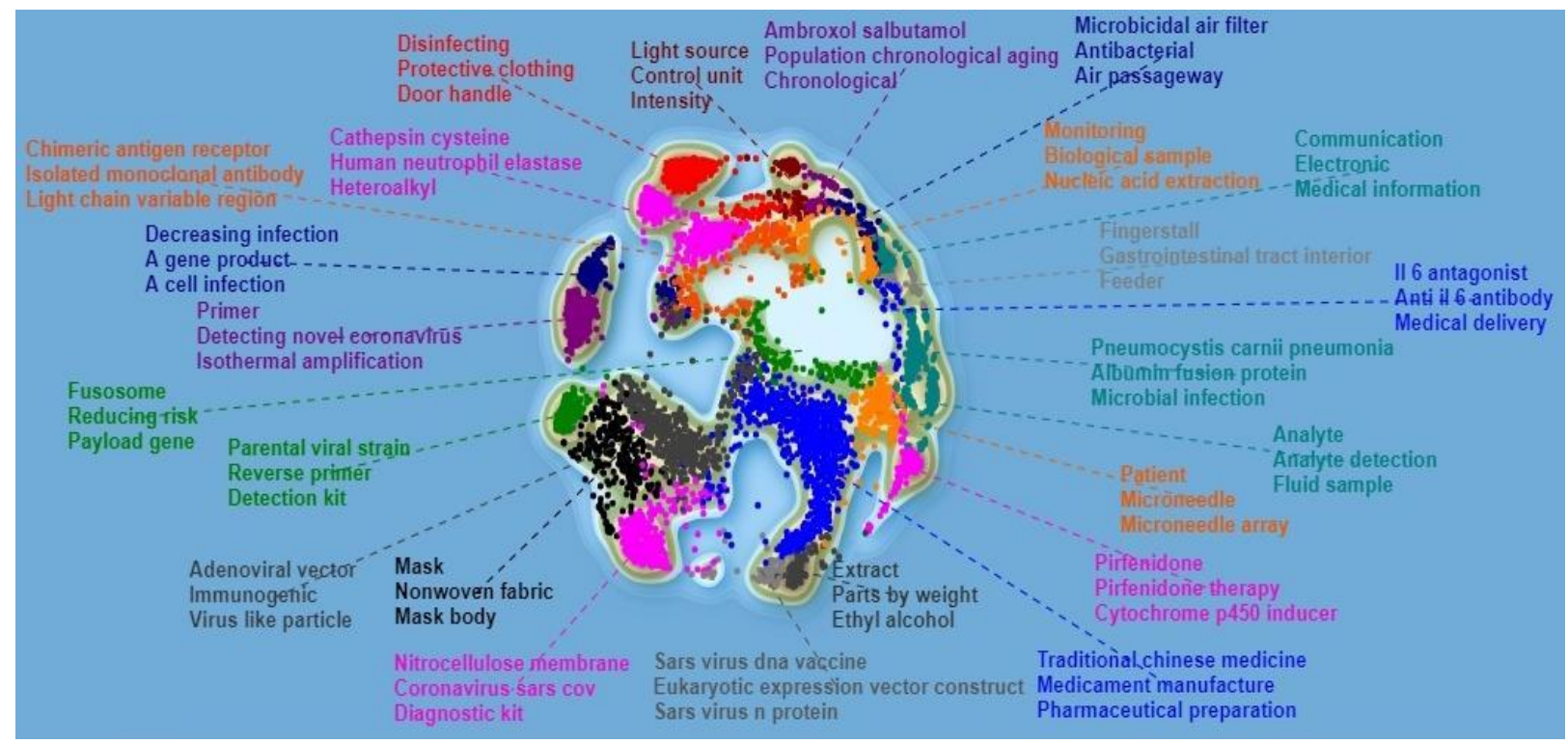

Fonte: Orbit (2020).

Os clusters estão associados com as soluções tecnológicas necessárias para o enfrentamento de uma pandemia, sendo os três principais temas: diagnóstico e identificação da doença; tratamento da doença (fármacos e vacinas); e equipamentos como máscaras filtros e métodos de esterilização. Dentre os clusters, destaca-se o em azul, que representa os pedidos de patentes da Medicina Tradicional Chinesa, fabricação de medicamentos e preparação farmacêutica. Segundo Nascimento Junior et al. (2020) a China é conhecida pelo uso de medicamentos à base de plantas tradicionais no trato de doenças, inclusive as virais. Em seguida, tem-se o cluster em cinza escuro com maior concentração de patentes apresentando vetor adenoviral, imunogênico e vírus como partícula.

Para análise de cluster por período, foram identificados os cinco mais ocorrentes sendo destacado na Figura 5 em cada agrupamento os três mais evidentes.

Figura 5: Clusters por período.

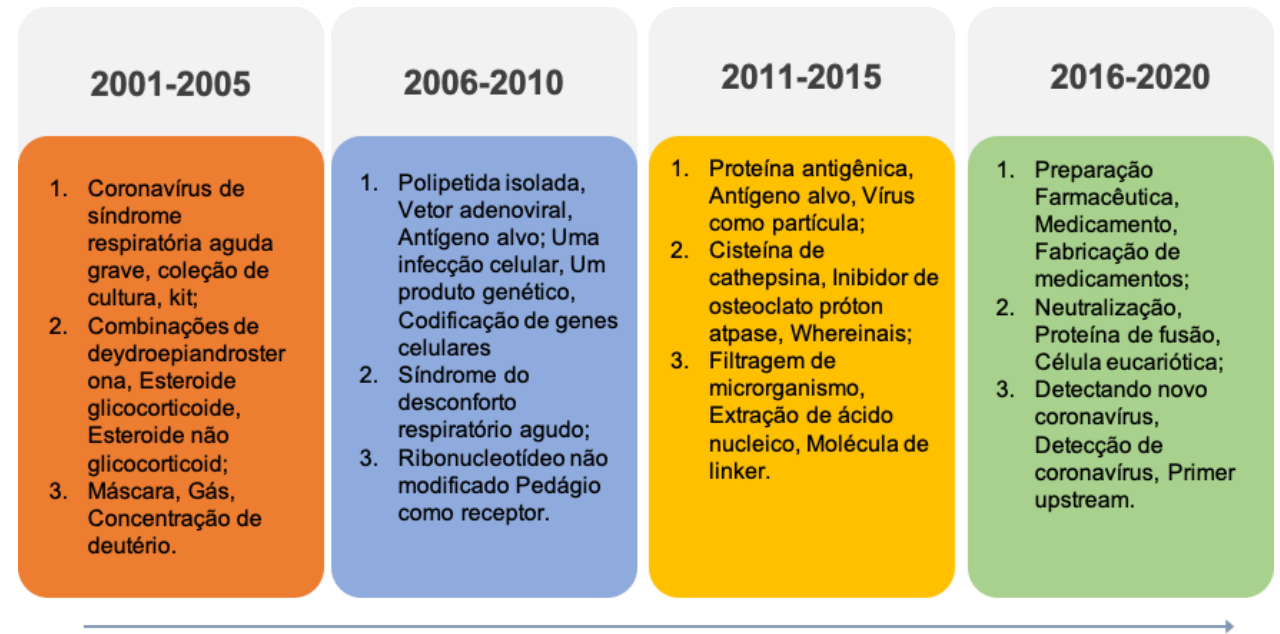

Fonte: Elaboração dos autores (2020). 
O exame dos clusters dos pedidos de patentes por período aponta algumas possíveis relações entre os surtos. No recorte de 2001-2005, onde se propagou o SARS e a NL63, observa-se a ênfase para kits e máscaras, enquanto entre 2011-2015, surto da MERS, a ênfase está relacionada a tratamento e 2016-2020 medicamentos e testes.

No Gráfico 4, observa-se o agrupamento de áreas de conhecimento, sendo a cor uma representação da quantidade de documentos associadas às respectivas áreas.

\section{Gráfico 4: Domínio tecnológico baseado nos códigos de Classificação Internacional de Patentes (CIP).}

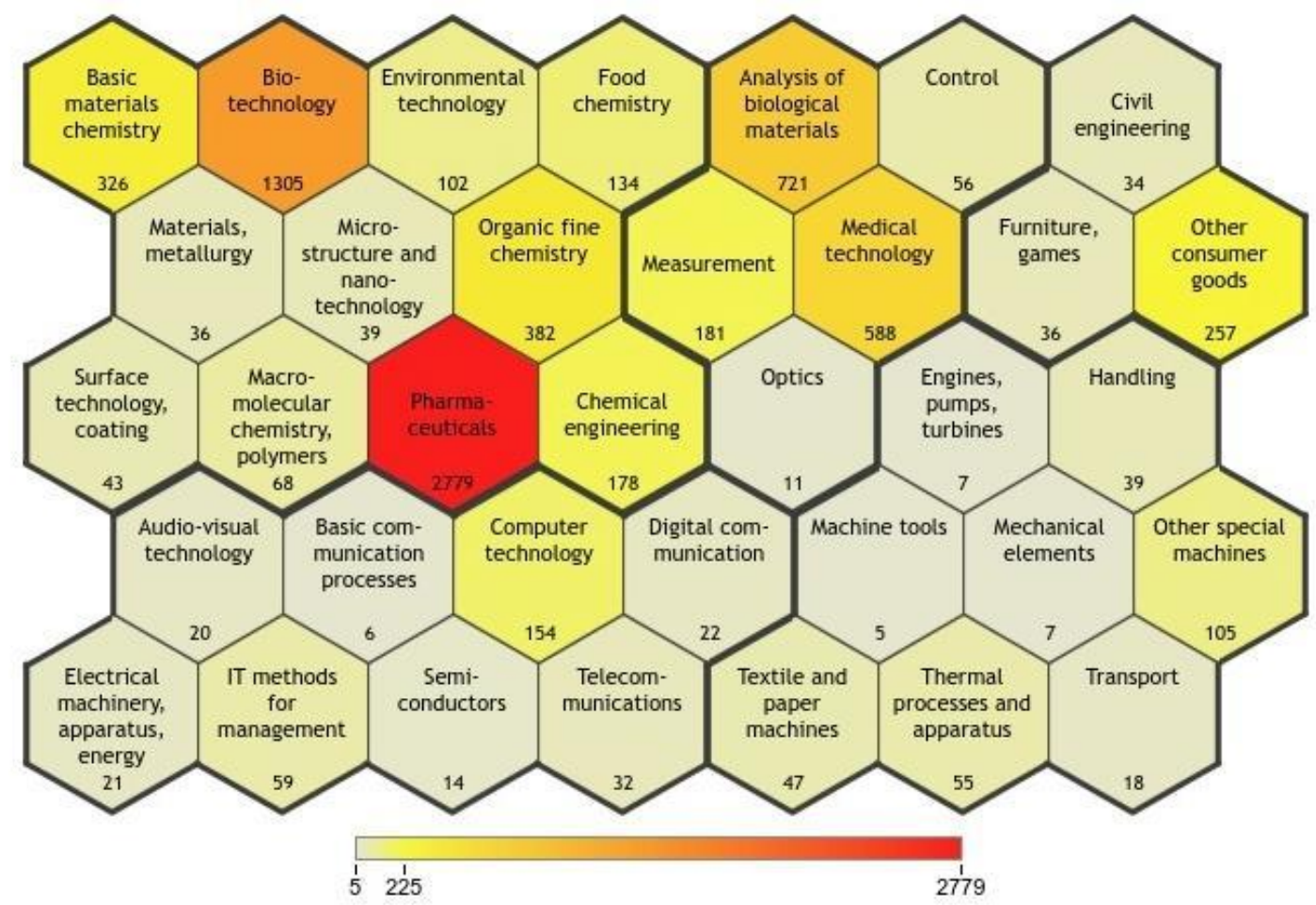

Fonte: Orbit (2020).

Os grupamentos predominantes dispostos do Gráfico 5, são de pedidos de patentes farmacêuticas e de biotecnologia. É possível observar também uma presença significativa do domínio tecnológico sobre análise de materiais biológicos e tecnologia médica. Ressalta-se que as solicitações de patentes podem ser representadas em várias categorias diferentes, pois as categorizações por domínio de tecnologia baseiam-se em agrupamentos de código CIP.

A predominância na área de farmacêutica pode estar associada à importância das vacinas para saúde pública, promovendo a prevenção de grandes pandemias, no entanto o surgimento de novos vírus e de novas cepas virais, como por exemplo o SARS-COV-2, indicam que o setor farmacêutico e o da biotecnologia se manterão impulsionados como aqueles de maior desenvolvimento tecnológico e aportes de recursos.

Deste modo, o desenvolvimento de vacinas é necessário para combater doenças como HIV ou malária, inclusive para promover melhorias nas vacinas existentes, devido ao surgimento de novas cepas de patógenos (WIPO, 2012). 
As grandes áreas do conhecimento que se destacam no Gráfico 5 corroboram com a análise supracitada das três principais áreas de pedidos de patentes: diagnóstico, fármacos e equipamentos associados ao combate da pandemia.

O exame do domínio tecnológico dos pedidos de patentes por período, identificados pelos cinco mais ocorrentes, apresenta pouca variação entre as áreas farmacêutica, biotecnologia, análise de materiais biológicos e tecnologia médica e as manifestações dos surtos, química orgânica manteve-se um padrão de número de patentes para os três primeiros períodos, mas não apresentou incidência no último que apresentou a área de outros bens de consumo. Esse contexto não permite inferir se existe um alinhamento entre surtos, descobertas e patenteamento.

No Gráfico 5 observa-se a relação das quantidades de pedidos de patentes pelos cinco principais códigos CIP a cada quinquênio do recorte temporal proposto pela pesquisa.

É importante salientar que os códigos A61P-011/00, A61P-031/14, A61P-031/12 versam sobre medicamentos para doença respiratória, anti-infeccioso para vírus RNA e antivirais, respectivamente. Esses três códigos apareceram em todos os períodos de tempo analisados, mesmo que esses não estejam figurando entre os cinco principais em todos os quinquênios que estão dispostos no Gráfico 5. Esses códigos apresentam correlação com a grande área de farmacêuticos descrita anteriormente.

\section{Gráfico 5: Análise histórica do CIP.}

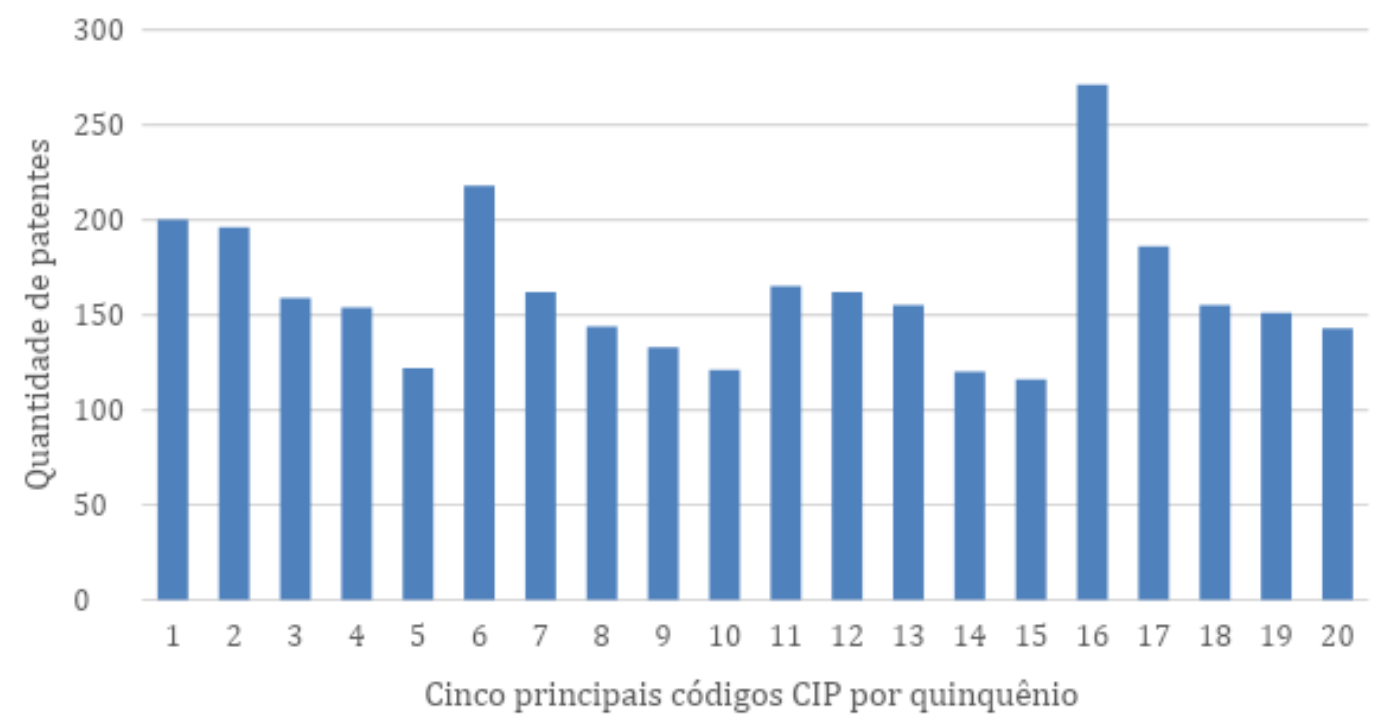

Fonte: Elaboração dos autores (2020).

Apesar dos diversos surtos desde o início do século XXI, apenas a partir do segundo quinquênio é que o código A61K-039/00 aparece como destaque (Gráfico 6). Esse está relacionado com preparações medicinais contendo antígeno ou anticorpos, ou em outras palavras, vacinas.

É importante destacar que o desenvolvimento de fármacos ocorre, em sua grande maioria, a partir de testes para comprovar a eficácia da substância, os quais são feitos pela indústria farmacêutica em equipamentos automatizados, podendo chegar até 1,5 milhões de testes por dia. Portanto, a produção de conhecimento de fármacos é rápida e por isso esses elementos apresentam-se como principal área do conhecimento a partir dos mais diversos gráficos desse trabalho. 
No entanto, o desenvolvimento de vacinas envolve o conhecimento biomolecular do vírus, assim como sua fisiopatologia, onde os ensaios são mais demorados e complexos. Portanto, o desenvolvimento de vacinas demora mais para atingir um resultado passível de ter interesse comercial, gerando uma patente, o que explica a menor frequência de código CIP associado a esse tipo de atividade (SINHA e VOHORA, 2018).

Os códigos C12Q-001/68, C12Q-001/70 e C12N-015/09 estão relacionados com testes ou métodos de medição envolvendo ácidos nucleicos, vírus e vetores para engenharia genética, respectivamente. Esses três códigos estão associados a técnicas utilizadas para o diagnóstico da doença, tema associado a diversos clusters do Gráfico 3.

Os resultados apresentados são corroborados pelo estudo de Musyuni et al. (2020) que demonstraram que as vacinas e kits de diagnóstico são as principais tecnologias protegidas para o tratamento de coronavírus e que até o momento não há vacina disponível para o tratamento de 2019 -nCoV, mas que existem potenciais invenções patenteadas.

Uma síntese dos dados levantados, agregando a eles um levantamento preliminar na base Scopus, cujos dados demandam de um tratamento efetivo, está disposto na Figura 4. O intuito de elencar o quantitativo da produção científica é destacar a importância de futuros estudos que agreguem uma ampla percepção do quadro exposto nas temáticas abordadas nos 44.108 artigos identificados.

Figura 6: Síntese global dos dados levantados.

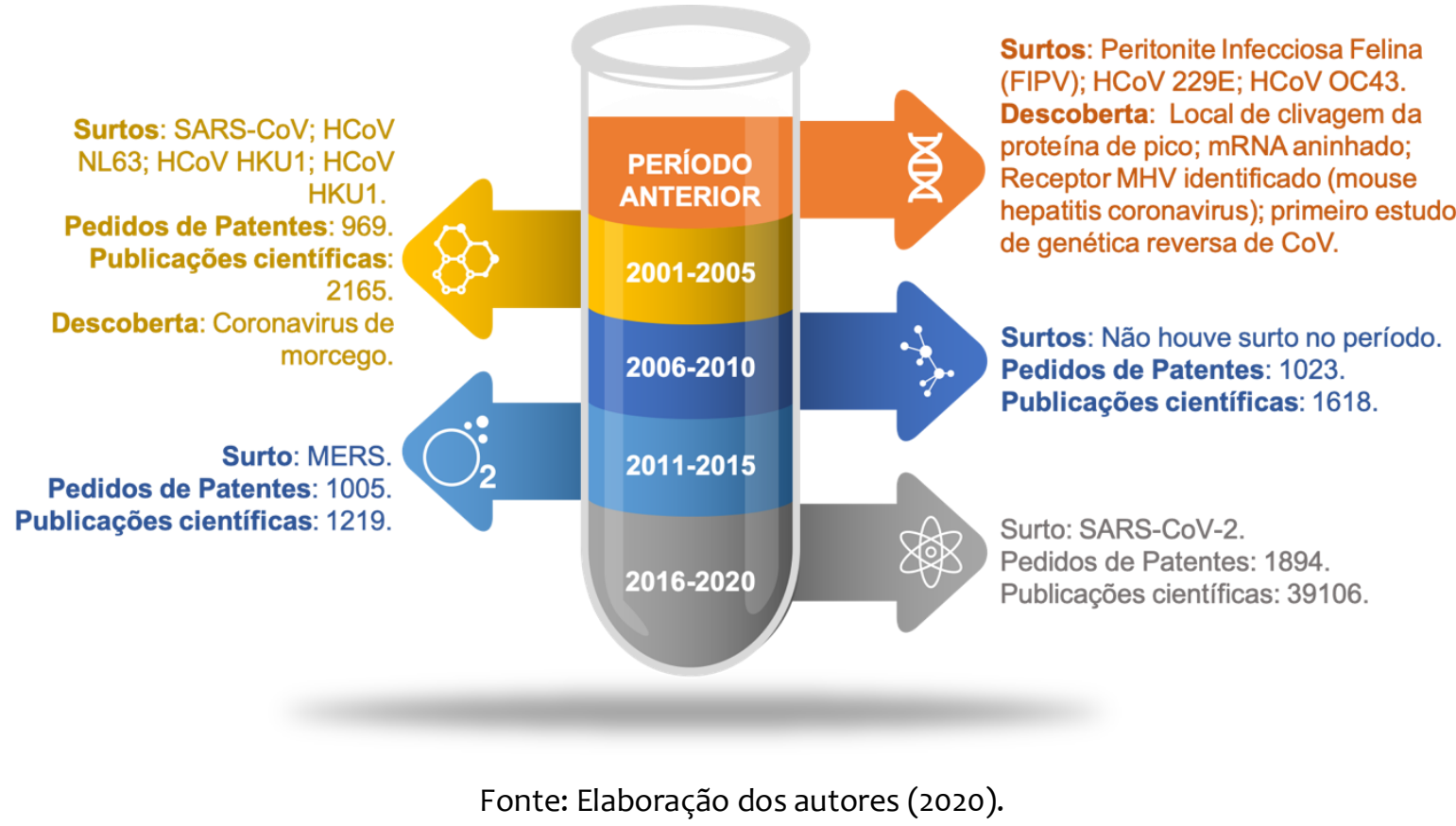

O exame global dos dados apresentados aponta que há um equilíbrio quantitativo nos pedidos de patenteamento nos três primeiros quinquênios analisados com uma leve alta no segundo, que não apresentou surto da doença.

Observa-se que as principais descobertas ocorreram no período anterior às análises e no primeiro recorte temporal apontando que elas estão relacionadas, provavelmente, a estudos com as doenças provocadas em animais e posteriormente em seres humanos. 
De maneira geral, a produção científica teve um volume maior no primeiro quinquênio, quando do surto especialmente do SARS, confirmando o que Weiss (2020) aponta quanto à relação dos surtos e os impactos significativos no campo de estudos sobre o coronavírus, antes pequeno e coeso, mas que se amplia e retrai à medida que o vírus surge e desaparece.

É evidente na Figura 6, que o surto de 2019, em curso, já apresenta um elevado número de pedidos de patentes e de publicações científicas, o que gera a expectativa de que seja ampliado de modo significativo as informações científicas e tecnológicas sobre o coronavírus permitindo que um amplo adensamento de conteúdos aos conhecimentos já existentes.

\section{CONCLUSÃO}

Essa pesquisa se propôs a examinar como se constituiu a relação entre manifestações da doença, descobertas científicas e produção tecnológica com o intuito de adensar conhecimentos que pudessem corroborar para a compreensão ampliada da pandemia global.

Para tanto, foi construído um arcabouço conceitual visando favorecer uma maior compreensão do contexto que envolve a ciência, a tecnologia e a inovação. Ainda amparada na literatura, foi composta a trajetória das manifestações das doenças causadas pela família coronavírus bem como dos avanços científicos ocorridos através do tempo. $O$ estudo teórico contemplou ainda o exame dos mais recentes estudos sobre patentes relacionados à família do vírus, sob diferenciados prismas.

A construção desse alicerce teórico foi efetuada para permitir que as análises fossem realizadas com o intuito de responder a seguinte questão norteadora da pesquisa: há um alinhamento entre a trajetória dos surtos, as descobertas e as tecnologias protegidas para as doenças causada pela família viral coronavírus?

De uma maneira geral, a partir das análises efetuadas, é tácito observar que não há um alinhamento entre o que se vivenciou dos surtos, as descobertas realizadas pelas pesquisas e a produção tecnológica dimensionada pelos pedidos de patentes. É possível observar, em raras situações, a existência de uma sinergia entre esses três elementos, mas, no geral, este entrelaçamento entre a realidade, as descobertas científicas e as tecnologias protegidas ainda representa uma área cinzenta em termos de eles tecerem um gerenciamento de conhecimento que contribua para o avanço sob todos os aspectos.

Futuros trabalhos dessa natureza poderão contribuir para o aprimoramento dessa pesquisa no sentido de buscar ampliar o entendimento de aspectos inerentes à produção científica, vista superficialmente nesse estudo, bem como a percepção mais ampla do quadro evolutivo das descobertas.

Em prol da geração de mais benefícios para a sociedade como um todo, é necessário que os produtores de conhecimento científico e tecnológico promovam um efeito catalizador do conjunto de resultados obtidos.

A democratização da ciência e da tecnologia, o aumento da conectividade global e a maior disponibilidade de dados que compõem o contexto da pandemia do covid-19, sobretudo pela ampla adoção dos preceitos da Ciência Aberta, deverá dinamizar este diálogo e promover mudanças significativas que impactarão no cenário póspandêmico. 


\section{REFERÊNCIAS}

GARBINO, J. et al. A prospective hospital-based study of the clinical impact of nonSevere Acute Respiratory Syndrome (Non-SARS): related human Coronavírus infection. Clinical Infectious Diseases, v. 43, n. 8, p. 1009-1015, Oct. 2006. Disponível em: https://academic.oup.com/cid/article/43/8/1009/341273. Acesso em: 05 jun. 2020.

FAN, Y. et al. Bat Coronavíruses in China. Viruses, v. 11, n. 3, p. 210-224, Mar. 2019. Disponível em: https://www.ncbi.nlm.nih.gov/pmc/articles/PMC6466186/. Acesso em: 13 ago. 2020.

GARCIA, J. C. R. Patente gera patente?. TransInformação, v. 18, n. 3, p. 213-223, set. 2006. Disponível em: https://www.scielo.br/scielo.php?pid=S0103-

37862006000300005\&script=sci_abstract\&tlng=pt. Acesso em: 12 ago. 2020.

INSTITUTO NACIONAL DA PROPRIEDADE INDUSTRIAL. Patente COVID. Rio de Janeiro: INPI, 2020. Disponível em: https://www.gov.br/inpi/pt-

br/servicos/patentes/tecnologias-para-covid-19/Patente_COVID. Acesso em: 13 ago. 2020.

INSTITUTO NACIONAL DA PROPRIEDADE INDUSTRIAL. Guia para o IPC. Rio de Janeiro: INPI, 2019. Disponível em:

http://ipc.inpi.gov.br/classifications/ipc/ipcpub//media/guide/pt/guide_ipc.pdf. Acesso em: 10 ago. 2020.

KUMAR, V.; JUNG, Y. S.; LIANG, P. H. Anti-SARS Coronavírus agents: a patent review (2008 - present). Expert Opinion On Therapeutic Patents, v. 23, n. 10, p. 1337-1348, ago. 2013. Disponível em:

https://www.tandfonline.com/doi/full/10.1517/13543776.2013.823159. Acesso em: 02 jun. 2020.

MACHUCA-MARTINEZ, F.; AMADO, R. C.; GUTIERREZ, O. Coronavíruses: a patent dataset report for research and development (r\&d) analysis. Data in Brief. v. 30, p. 113, jun. 2020. Disponível em:

https://www.sciencedirect.com/science/article/pii/S2352340920304455. Acesso em: 28 jul. 2020.

MCFEE, R. B. Human pathogen Coronavíruses: an overview. Disease-A-Month, v. 66, n. 9. p. 1-3, Jul. 2020. Disponível em:

https://www.sciencedirect.com/science/article/pii/So011502920301280?via\%3Dihub.

Acesso em: 02 ago. 2020.

MICHELLE HSIANG, M. Coronaviridae webpage. 1999. Disponível em:

https://web.stanford.edu/group/virus/1999/mhsiang/corona.html. Acesso em: 12 maio 2020.

MUSYUNI, P. et al. A case study: analysis of patents of Coronavíruses and covid-19 for technology assesment and future research. Current Pharmaceutical Design, v. 26, p. 13, Jul. 2020. Disponível em: doi.org/10.2174/1381612826666200720233947. Acesso em: 02 ago. 2020.

NASCIMENTO JÚNIOR, J. A. C. et al. SARS, MERS and SARS-CoV-2 (COVID-19) treatment: a patent review. Expert Opinion on Therapeutic Patents, v. 30, n. 8, p. 567- 
579, Jul. 2020. Disponível em:

https://www.tandfonline.com/doi/full/10.1080/13543776.2020.1772231. Acesso em: 02 ago. 2020.

ORBIT. Questel Orbit. França: Questel, 2019 Disponível em: https://www.questel.com/business-intelligence-software/orbit-intelligence. Acesso em: 04 ago. 2020.

PERLMAN, S.; NETLAND, J. Coronavíruses post-SARS: update on replication and pathogenesis. Nature Reviews Microbiology, v. 7, n. 6, p. 439-450, May 2020.

Disponível em: https://www.nature.com/articles/nrmicro2147.pdf. Acesso em: 02 ago. 2020.

PRIESNITZ, M. C. et al. Prospecção da produção tecnológica da Fisioterapia. In: MOSTRA DE INICIAÇÃO CIENTÍFICA, PÓS-GRADUAÇÃO, PESQUISA E EXTENSÃO, 15., 2015, Caxias do Sul. Anais eletrônicos.... Caxias do Sul: UCS, 2015. p. 1-8. Disponível em: http://www.ucs.br/etc/conferencias/index.php/mostraucsppga/xvmostrappga/paper/ viewFile/4204/1316. Acesso em: 19 jun. 2019.

PYRC, K.; BERKHOUT, B.; VAN DER HOEK, L. Identification of new human Coronavíruses. Expert Review of Anti-Infective Therapy. v. 5, n. 2, p. 245-253, Apr. 2007. Disponível em: https://www.tandfonline.com/doi/full/10.1586/14787210.5.2.245.

Acesso em: 05 jun. 2020.

QUINTELLA, C. M. et al. Prospecção tecnológica como uma ferramenta aplicada em Ciência e Tecnologia para se chegar à Inovação. Revista Virtual de Química, v. 3, n. 5, p. 406-415, dez. 2011. Disponível em: http://rvq.sbq.org.br/detalhe_artigo.asp?id=561. Acesso em: 07 ago. 2020.

SINHA, S.; VOHORA, D. Drug discovery and development. Pharmaceutical Medicine And Translational Clinical Research, p. 19-32, 2018. Disponível em: https://www.sciencedirect.com/science/article/pii/B978012802103300002X. Acesso em: 11 ago. 2020.

SCHWARTZMAN, S. et al. Ciência e tecnologia no Brasil: uma nova política para um mundo global. São Paulo: FGV, 1993. Disponível em: http://www.schwartzman.org.br/simon/scipol/novapol.pdf. Acesso em: 10 ago. 2020.

TECNOPUC. Patente. Porto Alegre: PUCRS, 2020. Disponível em: https://www.pucrs.br/tecnopuc/transferencia-de-tecnologia/propriedadeintelectual/patente/. Acesso em: 10 ago. 2020.

TIETZE, F. et al. Crisis-critical intellectual property: findings from the covid-19 pandemic. Centre for Technology Management Working Paper Series, n. 2, p. 1-19, Apr. 2020. Disponível em: https://papers.ssrn.com/sol3/papers.cfm?abstract_id=3569282. Acesso em: 17 ago. 2020.

VAN DER HOEK, L. et al. Identification of a new human Coronavírus. Nature Medicine, v. 10, n. 4, p. 368-373, Mar. 2004. Disponível em:

https://www.nature.com/articles/nm1024?fbclid=IwAR1dwFkj6wE8m9og3cl7ejuon5U DSBBPayoXTZWKgtc36xJ5eX1_wRbfoc. Acesso em: 05 jun. 2020. 
WEISS, S. R. Forty years with Coronavíruses. Journal of Experimental Medicine, v. 217, n. 5, p. 1-4, Mar. 2020. Disponível em:

https://rupress.org/jem/article/217/5/e20200537/151597/Forty-years-with-

CoronavírusesForty-years-with. Acesso em: 10 ago. 2020.

WORLD INTELLECTUAL PROPERTY ORGANIZATION. Patent landscape report on vaccines for selected infectious diseases. Genebra: WIPO, 2012. Disponível em:

www.wipo.int/patentscope/en/programs/patent_landscapes/reports. Acesso em: 12 ago. 2020.

YANG, K. L. et al. Analysis of traditional chinese medicine from patent information sharing platform of Coronavírus disease 2019 (COVID-19). Zhongguo Zhongyao Zazhi, v. 45, n. 13, p. 3001-3006, Jul. 2020. Disponível em:

doi.org/10.19540/j.cnki.cjcmm.20200330.5. Acesso em: 01 ago. 2020. 